\title{
Cuando lo "nuevo" es tan "viejo" como "nuevo" lo "viejo". El movimiento de derechos humanos durante la última dictadura militar en Argentina. El papel del Partido Comunista de Argentina y la Liga Argentina por los Derechos del Hombre (1976-1983)
}

\section{Natalia Casola*}

\section{Presentación}

En las últimas décadas, América Latina registra un fuerte incremento en los estudios sobre los procesos sociales vinculados a los pasados dictatoriales y las memorias de los mismos. Sin embargo, algunos temas, al menos en Argentina, aun no han recibido atención suficiente. El papel de los partidos políticos, especialmente de izquierda, durante la dictadura y su vinculación con el movimiento de derechos humanos es, sin lugar a dudas, uno de ellos. Esta vacancia de trabajos es aun más inquietante si se tiene en cuenta la influencia alcanzada por las izquierdas en los años anteriores al golpe de Estado de 1976.

La atención que la historiografía académica dedicó al estudio de las organizaciones armadas y la violencia política contribuyó, en buena medida, a

* Profesora de Historia, Programa Historia Oral, Facultad de Filosofía y Letras - Universidad de Buenos Aires (UBA). 
obturar la estructuración de un campo que considere la pluralidad de corrientes de izquierda, siendo habitualmente reducidas a la historia de Montoneros y el PRT (Gillespie, 1987; Pozzi, 2001). En el mismo sentido, la desarticulación de estas organizaciones con posterioridad al golpe afianzó la difusión de un relato que va de la derrota político-militar a la emergencia de un "nuevo" actor que reordena y reagrupa a los sectores opositores a la dictadura alrededor de la demanda de derechos humanos.

Algunos de los trabajos más influyentes sobre el movimiento de derechos humanos se nutrieron de los enfoques teóricos sobre movimientos sociales provenientes fundamentalmente de Europa. Enfatizaron las nuevas formas de manifestación ciudadana y la ruptura con los horizontes del marxismo y la teoría de la lucha de clases. El acento en las razones humanitarias fue interpretado como un proceso de evolución democrática llamado a profundizar en el futuro (Jelin, 1985, 2005).

De modo que, en estos trabajos, la experiencia que los militantes de diversas organizaciones aportaron a la (re)organización del movimiento de denuncia a la dictadura fue habitualmente soslayada. Las versiones que sobre el pasado consiguieron imponerse fueron moldeadas por el clima de transición democrática. Aunque con portavoces y contenidos diferentes, casi todos los relatos coincidieron en la condena de la violencia política y en la necesidad de reemplazarla por construcciones políticas que apuntaran a crear consensos. En el clima de devaluación de los proyectos revolucionarios, la postulación de los valores humanitarios venía a sustituir los “viejos" esquemas de confrontación por otros más acordes con los "nuevos" tiempos.

Sin embargo, el movimiento de derechos humanos estuvo disputado por distintas orientaciones políticas que representaban la alianza entre actores diferentes, por ejemplo, algunos partidos políticos y sectores de la iglesia.

El caso del Partido Comunista es un ejemplo claro de lo anterior. Suele reducirse su papel a las posiciones de condescendencia con el gobierno militar Carlos Zamorano., desconsiderando que esta política coexistía con el activo desempeño de sus militantes al interior de la Liga Argentina por los Derechos del Hombre (LADH) y otros organismos. El aporte específico de la LADH al movimiento de derechos humanos tampoco ha sido analizado en profundidad. Sin embargo es a partir de la experiencia de ese organismo que se organizan las primeras acciones públicas de los familiares de las víctimas de la represión dictatorial, más allá de los recorridos individuales. 
La trayectoria de los organismos que existían con anterioridad a 1976 fue clave para la organización inicial del movimiento de derechos humanos durante la dictadura. La labor de la LADH y de la APDH (fundada en diciembre de 1975) facilitó la búsqueda centralizada de los familiares. Por otro lado, es en oposición a estos organismos que van surgiendo nuevos agrupamientos poniendo en evidencia la existencia de profundas diferencias. Como dijera Raúl Veiga (1985, p. 22): "Las mencionadas diferencias no son sólo de procedimiento sino de fondo. Las consignas programáticas, el análisis de la realidad y la política de movilización toman formas diferentes según el organismo de que se trate."

Este artículo no se propone describir cronológicamente la política del PCA en relación a la denuncia de las violaciones de los derechos humanos durante la dictadura militar, sino ofrecer una descripción de sus principales posturas y fundamentos, y su traducción práctica como principal fuerza política al interior de la LADH.

Por otro lado, mediante el análisis de un caso, se busca contribuir a la recolocación del papel de los militantes en el movimiento de derechos humanos. Este último aspecto, minimizado en los relatos de las luchas contra la dictadura, tiene sin embargo derivas que aun no han sido suficientemente analizadas. Se trata de tender puentes entre épocas, poniendo de relieve que la dictadura de 1976 coronaba un proceso de evolución del terrorismo de Estado que comenzó, como mínimo, en 1973. Pero también, que el desplazamiento hacia las reivindicaciones humanitarias era el resultado lógico del cambio en la tendencia de la relación de fuerzas. Sin embargo, aunque los proyectos revolucionarios fueron derrotados, la experiencia política acumulada sobrevivió y se regeneró en la organización del campo opositor a la dictadura, especialmente en los organismos de derechos humanos.

Otra arista que aportaría a la reflexión sobre la complejidad de las alianzas en tiempos de la dictadura es el análisis de las mutuas implicaciones que resultan de la actividad común entre militantes experimentados y familiares que son empujados a la búsqueda de las víctimas. Así como los militantes políticos que participaron de los organismos no podían evitar aportar su perspectiva partidista a la política del movimiento, a la inversa, su participación en esos espacios plurales ejerció una influencia que luego se trasladaría a sus organizaciones políticas. Dar cuenta de esas relaciones permitirá superar una mirada extendida en Argentina que opone a los partidos políticos con los movimientos sociales. 
El presente artículo pretende aportar a los problemas señalados a partir del caso del Partido Comunista. En primer lugar, describe a grandes rasgos la política seguida por el PCA a partir de 1976 y sus fundamentos. Luego repone el papel de la Liga Argentina por los Derechos del Hombre. Se analiza su política como organismo de derechos humanos vinculado históricamente al comunismo, pero también su influencia en la configuración de un movimiento mayor.

\section{El "mal menor"}

Producido el golpe de Estado el 24 de marzo de 1976, el PCA decide mantener y reforzar la propuesta que venía desenvolviendo en el último año: llamar a la conformación de un gobierno de coalición cívico militar para cerrar las filas al ascenso del llamado "pinochetismo".

Como otros partidos políticos y sectores civiles, el PCA consideraba que el Gral. J. R. Videla encarnaba las posturas "profesionalistas" dentro de las Fuerzas Armadas. Aunque el golpe no era recibido como una buena noticia, consideraban que la situación anterior debía concluir de algún modo, y que el arribo de Videla a la conducción de la Junta Militar no representaba la salida más temida. Si bien la suspensión de las actividades políticas era vista con preocupación, por el momento, el principal peligro seguía siendo la consumación de un "golpe" de los militares llamados "pinochetistas". Estos últimos anidaban en la Marina y en algunos sectores del Ejército como en el Tercer Cuerpo, dirigido por Luciano Benjamín Menéndez, con centro en la provincia de Córdoba, en conjunción con las bandas paraestatales de derecha que venían actuando a su libre albedrío desde fines de 1973. En el análisis que hacía el PCA, la presencia de estos sectores debilitaba la posición de Videla, que era presionado para que profundice la represión sobre el movimiento popular en aras de la lucha contra la "subversión". En ese marco, el Partido Comunista optaba por lo que suponía la defensa del "mal menor": se lanzaba

1 La denominación "pinochetismo" es exclusivamente utilizada por el Partido Comunista de Argentina para hacer referencia a los sectores ultraderechistas dentro de las Fuerzas Armadas Argentinas. Al referir directamente al dictador chileno Pinochet, el término tenía un carácter indicativo sobre lo que cabría esperar si estos sectores se imponían en la conducción de la Junta Militar. Fuera del PCA, los usos más extendidos para denominar a estos sectores dentro de las FFAA, eran el de "halcones" y "palomas" o "duros" y "blandos". 
a una campaña de apoyo a Videla y exigía simultáneamente una convocatoria a los sectores civiles con el propósito de fortalecer el rumbo del gobierno y bloquear el ascenso fascista. El objetivo final era forzar al gobierno a establecer un diálogo permanente con los partidos políticos en pos de un proceso de institucionalización. ${ }^{2}$

En consecuencia, toda expresión contraria al Presidente contribuiría, en la lectura del PCA, a fortalecer al sector "pinochetista" dentro de las Fuerzas Armadas. En su visión, quienes conspiraban contra el gobierno intentando enfrentarlo al pueblo y en primer lugar a la clase obrera contribuían a imponer un régimen pinochetista. De allí que, en primer lugar, criticaran abiertamente a los sectores llamados "ultraizquierdistas" y se proclamaran contra la violencia "de cualquier signo":

El presidente de la Nación, teniente general Videla, ha reiterado en numerosas oportunidades su compromiso de facilitar el retorno del país a las instituciones democráticas. Pero son muchas las maniobras que se llevan a cabo para que ello no ocurra y para que la situación desemboque en un régimen pinochetista. El terrorismo de izquierda, duramente golpeado, facilita esas maniobras y el impune terrorismo de derecha forma parte de ellas. (Fundamentos, 1976, p. 290).

La expectativa en el sector encabezado por Videla fue alimentada por el mantenimiento de la legalidad del partido y por la actitud parcialmente abierta adoptada por el gobierno en relación a la Unión Soviética. La apertura política en el plano internacional y el pragmatismo económico que asumiría la Junta Miliar, implicaba una ruptura respecto de los cánones impuestos por la Guerra Fría. Esa mayor desideologización fue leída por los comunistas como un rasgo de progresismo que diferenciaba al autodenominado Proceso de Reorganización Nacional de las dictaduras anteriores. En la misma dirección, las crecientes contradicciones entre el régimen militar argentino y el gobierno estadounidense bajo la presidencia de James Carter (1977-1981) serán interpretadas como señales favorables.

2 Un ejemplo de la voluntad de los comunistas de mantener un diálogo con el gobierno militar lo ofrece la participación de los dirigentes Jesús Mira, Juan Carlos Dominguez y Rodolfo Ghioldi de una comida realizada en 1978 junto a otras fuerzas y personalidades a la que acudió Videla. 
El mantenimiento de la legalidad partidaria era un factor importante que explica esa postura conservadora. El rechazo a denominar al régimen como una dictadura y a vincular los secuestros con el accionar estatal sería explicado (en primer lugar a su militancia) a la luz de la necesidad de no poner en riesgo la legalidad.

La decisión de no enfrentar al régimen explica por qué, con excepción de algunos casos particulares, el conjunto de los militantes del partido no pasó a la clandestinidad. Al contrario, la orden de la dirección del PCA consistió en mantener los locales y, frente a una posible detención, no ocultar la pertenencia al Partido Comunista. Por el mismo motivo, no existió una política de repliegue hacia el exilio; al contrario, los militantes eran instados a quedarse en el país y, sobre la base de una política de no confrontación, acumular fuerzas para cuando la tendencia cambiara de signo. En la perspectiva de los dirigentes comunistas, el pase a la clandestinidad hubiera implicado alertar a las fuerzas represivas sobre los verdaderos propósitos del partido arriesgándose a ser proscriptos. En esa lógica política, la pertenencia al PCA debía servir como una especie de certificado de buen comportamiento. Las críticas a la guerrilla eran públicas y el comunismo también consideraba que representaban un obstáculo para el desarrollo de la democracia.

De manera que, en lugar de denunciar que la "lucha contra la subversión" se había transformado en una excusa para aplicar la represión sobre amplios sectores de la sociedad, el Partido Comunista, haciéndose eco de los planteos del gobierno, se esforzaba por dejar en claro que nada los unía con el terrorismo al que, recordaban, ellos mismos se oponían. ${ }^{3}$

Sin embargo, contra los pronósticos, esa política condujo a que las medidas de seguridad interna se relajaran, facilitando la represión sobre sus filas. ${ }^{4}$

Las numerosas desapariciones de militantes del Partido Comunista durante 1976 y 1977 fueron sistemáticamente denunciadas en el periódico partidario Tribuna Popular y Movimiento Obrero. En todos los casos se destacaba que se trataba de afiliados del PCA, es decir, de personas sin vínculos con la subversión. Asimismo, estas denuncias ponían en evidencia que las bandas

3 Hasta fines de la dictadura el PC sostendrá esas posiciones.

4 Más del 90\% de los desaparecidos del PC fueron secuestrados entre 1976 y 1977. En este sentido, la represión sobre el PC sigue las mismas pautas que para el resto de las organizaciones si se tiene en cuenta que el 76,6\% de las desapariciones en el país se produjeron hasta 1977. Secretaría de Derechos Humanos de la Nación, base CONADEP. 
armadas de la ultraderecha no habían sido neutralizadas; en los casos en los que trascendía la posible participación de las Fuerzas Armadas en los operativos, se dejaba sentado que de ser cierto implicaría una grave contradicción con los supuestos objetivos del Proceso.

\section{La Liga Argentina por los Derechos del Hombre y el comunismo}

El papel del Partido Comunista en la LADH fue muy activo. Aunque estatutariamente la LADH sea independiente de los partidos políticos y su Consejo Directivo ha incorporado en todas las épocas a personalidades de diferentes pertenencias políticas, sus posiciones siempre estuvieron identificadas con las del Partido Comunista. La historia de la LADH se encuentra compenetrada con la de otras organizaciones surgidas en el contexto de la segunda pos-guerra y asociadas al Movimiento Comunista Internacional, como, por ejemplo, el Movimiento por la Paz. La LADH se vincula orgánicamente desde entonces a la reconstituida ${ }^{5}$ Federación Internacional por los Derechos del Hombre, con sede en París.

El apoyo a estas organizaciones se enmarcaba en una política de amplitud definida desde el Kominform, que perseguía el objetivo de sacar del aislamiento a los partidos comunistas haciendo posible la concreción de frentes amplios en la base. Sin embargo, se trataba de una política contradictoria; el comunismo argentino, aun queriendo practicar la amplitud, se esforzaba por conservar el control político sobre esos movimientos desdibujando las fronteras que los separaba del partido. Al revés, el clima impuesto por la Guerra Fría funcionó como una barrera que hacía que las diversas fuerzas "progresistas" a las que el PCA interpelaba mantuviesen una distancia prudencial, temerosas de ser tildadas de comunistas. De manera tal que, aunque la LADH no tuviese vinculación reconocida con el PCA, su influencia política era decisiva.

Cuando se produjo el golpe el 24 de marzo de 1976, la LADH contaba con cuarenta años de experiencia acumulada en la defensa de las libertades constitucionales y de las garantías individuales. Había atravesado varias dictaduras militares y había sido blanco de la represión en más de una ocasión.

5 Había sido creada en 1922. 
Históricamente su actividad se centró desde su fundación en la asistencia jurídica y material a los presos políticos y sus familias. Motorizada por ese partido en el contexto de las luchas antifascistas de los años 30 y 40, fue tomando una fisonomía acorde al programa de Frente Democrático Nacional sostenido por el PCA desde 1935 en adelante.

Esa experiencia acumulada durante décadas de represión a los militantes comunistas, marxistas y peronistas sería volcada en 1976.

\section{La LADH a partir de 1976}

Con el golpe de Estado el 24 de marzo de 1976, la actividad del partido se intensificó volcando a una parte importante de su militancia en la colaboración con el organismo. Aunque el comunismo también había dispuesto funcionarios en la APDH y algunos militantes se habían incorporado a Familiares de Desaparecidos y Detenidos por Razones Políticas (también Comisión de Familiares), su participación como fuerza política, a diferencia de la LADH, era equiparable a la de otros partidos.

El conjunto de la actividad de los familiares de las víctimas durante el primer año, más allá de los recorridos individuales por dependencias oficiales e iglesias, fue organizada en función de las indicaciones dadas por la $\mathrm{LADH}$. La presentación de Habeas Corpus perseguía el objetivo de motivar la acción de los tribunales. En segundo término, y sin dejar de lado los trámites legales, se indicaba que los familiares interpelen al Presidente ${ }^{6} \mathrm{y}$ ministros mediante cartas en las que se exponían los testimonios individuales. Con esas acciones no se esperaban respuestas positivas, sino crear mecanismos de publicidad de los casos y concitar la solidaridad y la movilización.?

Pero, además, la LADH sirvió como un punto de reunión para los cientos de familiares que luego de recorrer comisarías y dependencias oficiales comenzaban a agotar los recursos de la búsqueda. La puesta en común de las experiencias fue poco a poco transparentando la existencia de un plan

6 Por ejemplo, en ocasión del secuestro de la abogada Teresa Israel, su madre Clara B. de Israel envía una carta a la esposa de Videla solicitándole que interceda por la vida de su hija. "Ayude a salvar la vida de mi hija", 15 de marzo de 1977. Archivo de la LADH.

7 Los mismos pasos fueron seguidos en 1951 en ocasión del secuestro y desaparición del estudiante Mario Bravo. También se sigue esta secuencia en el caso del médico comunista Juan Ingalinella, secuestrado en junio de 1955 . 
represivo que contradecía abiertamente el discurso moderado adoptado por el Proceso.

El plan concebido por las Fuerzas Armadas se basaba en la clandestinidad y la desinformación. Ese desconocimiento que amplios sectores de la sociedad tenían sobre la magnitud del sistema de terror instalado permitió que los militares gozaran de un relativo consenso inicial. La mayoría de los testimonios coinciden en remarcar la incredulidad y la esperanza que acompañaron a los familiares de las víctimas de la represión en los primeros años. Una y otra vez, cuentan cómo fue su peregrinaje inicial y el proceso de desencanto producido frente a la ausencia de toda respuesta oficial.

De manera que la reunión de los familiares en la LADH fue un primer paso que permitió visualizar que no se trataba de casos aislados, sino de la generalización de un modus operandi que incluía el secuestro y la desaparición de las personas. Aunque existiera renuencia a vincular las desapariciones con la actividad del Estado, al menos era evidente que esas bandas terroristas gozaban de la impunidad oficial.

A pesar de que desde mediados de 1977 la responsabilidad de los militares en las desapariciones fue volviéndose más clara, hasta la visita de la Comisión Interamericana de Derechos Humanos (CIDH) en 1979, la tendencia del conjunto de los organismos era ocultarla. Se evitaba denunciar a los militares en la creencia que esa clase de insinuación podría perjudicar a las víctimas.

Más improbable es que la LADH desconociera los vínculos que existían entre los secuestros de personas seguidos de desaparición y las Fuerzas Armadas. No solo contaban con una larga experiencia previa en relación a la represión estatal, sino que habían tomado nota de la creciente intervención del Ejército en la represión desde febrero de 1975. De modo que la decisión de no denunciar los secuestros como parte de una política de terrorismo de Estado era consecuencia de una lectura política fuertemente influida por las posiciones del Partido Comunista.

En agosto de 1976, la Agencia de Noticias Clandestina, ligada a Montoneros y dirigida por Rodolfo Walsh denunció que los desaparecidos se encontraban en cautiverios clandestinos organizados por las Fuerzas Armadas y que el destino que les deparaba era la muerte. Meses después, en marzo de 1977, publicaba su "Carta abierta de un escritor a la Junta Militar", en la que denunciaba el carácter estatal y sistemático de las desapariciones. Es improbable que la dirigencia del PCA desconociera la información proporcionada por Walsh. 
En cambio, la LADH evitó producir declaraciones públicas en las que los secuestros y desapariciones aparecieran vinculados al accionar del Estado hasta 1979. En sintonía con las declaraciones del Partido Comunista, remarcaban los signos de diálogo de los militares como un paso adelante, las publicaciones de listados oficiales de detenidos como una señal de la voluntad gubernamental de transparentar la situación y correr el velo que ocultaba la verdad sobre el paradero de miles de personas. Estas afirmaciones eran acompañadas de una categórica distancia respecto de las organizaciones guerrilleras y una condena a la violencia sin importar de dónde provenga. Por ejemplo, en las declaraciones finales del Congreso Ordinario, de mayo de 1978, se expresaba:

Nuestra condena al terrorismo de todo signo así se presente con motivaciones pretendidamente ideológicas, como al terrorismo mercenario, es terminante. Lo condenamos porque es ante todo la negación de los derechos humanos, pero además, pretexto y catapulta para el de signo contrario y particularmente el ingrediente que necesitan para apartar al pueblo de sus actividades protagónicas en los procesos sociales. ${ }^{8}$

De manera que en los primeros años la $\mathrm{LADH}$ intentó deslindar las desapariciones del accionar del Estado, exigiendo al gobierno que, así como había reducido el accionar del terrorismo de ultraizquierda, debía asestar un golpe al terrorismo de la derecha. Si en 1976 el reclamo era sintetizado en la consigna "que el Estado monopolice la violencia", en 1978 fue levemente modificada, agregando la oración "dentro de la ética y la moral republicanas, por parte del Estado".

Esa mesura explica que hacia 1977 la LADH intentara convencer a los familiares que se acercaban a radicar la denuncia de que no asistieran a la Plaza de Mayo, que acciones osadas solo podían esperar una represalia mayor. En la práctica, las iniciativas de la $\mathrm{LADH}$ dentro del naciente mundo de las organizaciones de derechos humanos consolidaban un discurso que retardaba las posibilidades de conformación de un movimiento de denuncia.

Según Alberto Pendroncini, destacado letrado de la LADH, la consigna "que el Estado monopolice la violencia" afectó el trabajo de los abogados:

8 Declaración del XX Congreso Nacional Ordinario de la LADH, 26 y 27 de mayo de 1978, p. 24. Archivo de la LADH. 
[...] Significaba decir indirectamente que los grupos que secuestraban no pertenecían al aparato del Estado, y esta fue una de las causas mayores de pérdida de combatividad. No combatividad armada, sino de denuncia de la naturaleza de la dictadura militar en sus primeros años. Es decir, la afirmación, de la consigna de "recuperar para el Estado el monopolio de la fuerza" era renunciar a decir que estábamos frente a un terrorismo de Estado. Que no eran grupos sueltos, sino todo el aparato militar y policial del Estado lanzado a la represión criminal. [...] Era una manera, equivocada supongo, pero comprensible. Poco tiempo después dejó de ser comprensible, pero fue una manera de actuar en esa inmensa disparidad de fuerzas de la que hablábamos al principio. (Memoria Abierta, 2003a).

De manera que la política de la LADH puede conceptualizarse como de "organización sin confrontación". En otras palabras, aunque a lo largo de todo el periodo, la LADH acompañó todas las actividades públicas que se fueron desarrollando en unidad con el resto de los organismos de derechos humanos, y públicamente omitía la responsabilidad de las Fuerzas Armadas en la represión. La cautela inicial se transformó, a la postre, en un factor de confusión para los familiares y para una sociedad que desconocía o no quería (re)conocer la existencia del exterminio.

En la privacidad, los militantes de la LADH vinculados al PCA explicaban que las Fuerzas Armadas no eran monolíticas y que se debatían entre sectores fascistas y sectores moderados a los que había que intentar presionar en función de la apertura de un proceso de diálogo. Esta caracterización fue un factor de recurrente discusión interna con la Comisión de Familiares y con el resto de los organismos de derechos humanos.

Otro elemento que en la intimidad resultaba polémico era el factor internacional. Mientras para la LADH la defensa de la Unión Soviética no tenía discusión, para el resto de los organismos era evidente que los países socialistas actuaban en bloque con la dictadura en los foros internacionales. A la inversa, mientras la política de los Estados Unidos bajo la presidencia de Carter era vista con desconfianza por parte de los comunistas, para el resto de los organismos resultó un apoyo importante. Sin embargo, aunque estos debates habían ocupado un lugar en la privacidad de los vínculos intra-organismos, públicamente la LADH no hizo nada para impedir que la labor en Naciones Unidas y la CIDH prosperasen. Al contrario, frente a la visita de la Comisión perteneciente a la OEA, la LADH se transformó en un factor de organización muy importante. 
La cautela política, sin embargo, no impidió que la represión cayera sobre la LADH en varias ocasiones desde 1976. Entre los casos más conocidos se encuentra la desaparición de la abogada de la LADH y militante del PCA Teresa Israel el 8 de marzo de 1977.

\section{La Comisión de Familiares...}

Siguiendo una política aplicada sistemáticamente por la LADH a lo largo de su historia, en septiembre de 1976 impulsan la organización de la primera Comisión de Familiares, que al año siguiente tomaría el nombre de Familiares de Desaparecidos y Detenidos por Razones Políticas y Gremiales.

Los vínculos entre el viejo y experimentado organismo y la nueva Comisión aun no han sido suficientemente estudiados.

Numerosos testimonios de personas vinculadas a diferentes organismos remarcaron la influencia que la $\mathrm{LADH}$ tuvo sobre Familiares como un factor importante. Aunque esa influencia fuera comprensible, en primer lugar, por ser la LADH el organismo anfitrión de las reuniones y, en segundo lugar, por contar con una experiencia que el resto de los familiares no tenía, la presencia de militantes es recordada por muchas Madres que se acercaban a las reuniones como un elemento que generaba incomodidad.

Algunos testimonios de Madres de Plaza de Mayo dejan entrever que la decisión de conformarse como un agrupamiento nuevo se relaciona con la desconfianza a participar de la vida de un organismo que, como la LADH y Familiares, "politizaba” la búsqueda de los desaparecidos. Así como en los primeros tiempos las Madres negaban la militancia de sus hijos por temor a perjudicarlos, también temían que de asistir a Familiares quedarían vinculadas a la subversión, o sea, al comunismo, de acuerdo con el imaginario de la Guerra Fría.

Vinculado a lo anterior se encontraba el temor a ser "aparateadas" por personas con experiencia militante. Por ejemplo, Hebe de Bonafini cuenta:

9 Muchos testimonios de familiares sin experiencia militante concuerdan que su entorno aconsejaba el inmovilismo, "más hacés, peor es", recuerda Lita Boitano. Entrevista realizada por Gustavo Martuccio. Programa de Historia Oral de la Facultad de Filosofía y Letras, junio de 2006. 
Cuando Familiares funcionaba en la Liga. Y entonces había una persona con un micrófono que dirigía la reunión. Y vos te matabas pidiendo la palabra y era muy difícil que te la dieran. Siempre había tres o cuatro que por experiencia política, por supuesto, conseguían la palabra. Y además porque nosotras como madres, proponíamos cosas que para ellos eran muy descolgadas. ${ }^{10}$

También Ulises Gorini (2006), en su historia sobre las Madres de Plaza Mayo, repone esos temores. Cuenta que muchas de las mujeres que luego integrarían la agrupación Madres habían participado más o menos regularmente de las reuniones de Familiares en la LADH y que, sin embargo, por diversas razones, muchas no se incorporaban; pone como ejemplo el testimonio de María del Rosario para quien

[... la Liga... era una cosa muy formal, parecía un colegio. Nosotras teníamos que ir y quedarnos sentadas escuchando al que hablaba. Recuerdo muy bien a Esther Careaga, por ejemplo, otra madre, que siempre hablaba y proponía cosas y la hacían callar. ${ }^{11}$

Sin embargo, es la presencia de militantes experimentados lo que posibilita una rápida organización de los familiares de presos y desaparecidos. En este sentido, como la LADH, el desarrollo de la Comisión se dinamiza por la concurrencia de familiares que cuentan con experiencia política previa. Su núcleo dirigente estaba integrado por padres, madres o hermanos, que adscribían a una identidad política definida. Lucas y Lilia Orfanó eran militantes peronistas; Catalina Guagnini militaba en Política Obrera y Mauricio Eisenchlas en el Partido Comunista. Hilda de Velázco y Lita Boitano, en cambio, no eran militantes. Sin embargo, ambas conocían y señalan que aprobaban la militancia de sus hijos e hijas. Esa estrechez con la política les permitió denunciar las causas por las cuales sus hijos eran detenidos o desaparecidos. No se trataba de un error o exceso. Eran atacados por razones políticas y, por eso, decidieron incorporar esa denuncia al nombre del organismo.

El reconocimiento de la militancia de las víctimas los diferenciaría de organismos como Madres o Abuelas de Plaza de Mayo. Estos organismos

10 Entrevista a Hebe de Bonafini, citada en Casola y Martuccio (2007).

11 Entrevista citada en Gorini (2006, p. 79). 
evitaban mencionar la militancia de sus hijos ya sea por desaprobación, por desconocimiento o por temor a estar ofreciendo una evidencia funcional a la campaña ideológica del régimen militar.

A pesar de las diferencias políticas entre Familiares y la LADH, la convivencia era posible. La experiencia militante permitió que asumieran rápidamente la necesidad de cierta especialización. Dinamizó la actividad de Familiares, adoptando una estructura en la que las tareas estaban divididas en comisiones que, a su vez, eran centralizadas por un responsable. La militancia política acercaba a unos y otros, permitiendo que dialogaran en un lenguaje común:

Teníamos muy buenas discusiones, se peleaba, se discutía, claro, sin duda que fue mucho más político nuestro organismo, porque estaba mezclado, era como lo de la Asamblea, ahí también había muchos políticos en el staff permanente [...] El nuestro, las discusiones se hacían realmente muy políticas $[. .$.$] era toda gente militante... (Memoria Abierta, 2003b).$

Otro elemento importante que aglutinaba a ambos organismos era la organización de la asistencia a los familiares de los presos políticos. Los secuestros y desapariciones se habían transformado en un modus operandi que muchas veces invisibilizaba la situación de los detenidos en las cárceles de la dictadura. En este sentido, la persistencia del reclamo por parte de la LADH y de Familiares se vincula al esfuerzo por articular una estrategia que contemplaba la totalidad de la situación.

En consecuencia, el núcleo dirigente de Familiares no veía en los militantes del PCA una amenaza para su actividad. Aunque mantuviesen diferencias políticas, las posiciones de la $\mathrm{LADH}$ no levantaban sospechas en torno a la buena fe de sus militantes. Además, la LADH se mantuvo relativamente al margen de muchas decisiones vitales que, a la postre, transformaron a Familiares en un organismo más radicalizado. Es probable que la presencia abrumadora de familiares de desaparecidos vinculados a las organizaciones guerrilleras fuese un elemento de peso para que la LADH se mantuviese a distancia.

En oposición a estos comentarios, algunos testimonios indican que en la relación que se establece entre la Comisión de Familiares y la LADH las influencias fueron mutuas. Por ejemplo, algunos militantes del PCA que participaban de Familiares terminaron adoptando una posición crítica respecto 
de la línea del partido. Mauricio Eisenchlas, refiriéndose a la propuesta del partido de conformar un gobierno cívico militar, evalúa

[...Carlos Zamorano.] fue un error porque, bueno, los compañeros que teníamos personas desaparecidas teníamos un criterio completamente distinto al del partido y discutíamos en el partido... nosotros luchamos dentro del partido por nuestros desaparecidos, luchábamos yo creo que el Partido Comunista fue el único partido que sacó una publicación con los nombres de todos los desaparecidos comunistas, íbamos a la gente del gobierno a plantearle la gente desaparecida comunista. Lo que pasa que, bueno, hubo una lucha muy seria por esa concepción de los buenos y los malos que llevaron a muchos errores, que muchos compañeros junto conmigo discutíamos dentro del partido por una concepción de tratar de delimitar de que ciertos sectores todavía podían, en alguna forma, plantearse el problema de una salida cívico militar, que es tan célebre y, bueno, nosotros que estábamos en Familiares y en otros organismos de derechos humanos discutíamos dentro del partido sobre este problema. (Memoria Abierta, 2001b).

Otro ejemplo de esa influencia de los organismos sobre los militantes comunistas lo ofrece el caso del matrimonio de Enrique y Clara Israel. Ambos militantes de toda la vida del PCA, Enrique era el secretario de redacción de la revista Nueva Era y había sido durante décadas secretario de Codovilla. Cuando Teresa es secuestrada, Clara se incorpora a Familiares. Desde entonces, comienza a transitar una experiencia de lucha que la obliga a tomar una postura crítica respecto de la línea del partido. Enrique cuenta:

El partido comunista me apoyó, me apoyó. Pero me apoyó, digamos, sin cambiar la línea de no criticar a la dictadura militar. Porque erróneamente ellos creían, y yo también al principio, de que había un peligro pinochetista. Pero el peligro pinochetista ya estaba en el poder. Ya estaba. Era esta dictadura. Eran ellos los pinochetistas. Y nosotros con una mala información de los medios militares pensamos que podía venir el golpe pinochetista. [...] Era contradictorio en los hechos: tanto es así que al final yo decía "Aparición con vida" era la consigna de las Madres [enfatiza] y yo adopte esa posición, pero mi partido no. Y se vivió mal, porque inclusive en una manifestación - que ya me acompañaban muchos compañeros del partido que también decían "aparición con vida" - me acuerdo que íbamos con 
la manifestación y pasamos delante de la puerta del Comité de la Capital gritando "aparición con vida", y se nos hizo un vacío de los que decían que “aparición con vida” no se puede porque se contradecía con la línea del partido. Bueno... el partido después hizo la autocrítica de la consigna de que "aparición con vida" era correcto... [El partido] me ayudó en todo lo que era presentación, por ejemplo, escritos en la prensa, pagarme los avisos que los escribía yo todo, los escribía en un lenguaje un poco conciliador con la línea del partido y un poco crítica, tengo que reconocerlo, pero era así. Aparte teníamos información de que estaba con vida, entonces yo tenía también que cuidar de que no la afectara. Era una concepción equivocada, había que denunciarlos directamente todo. (Memoria Abierta, 2001a).

Como puede observarse en este testimonio, los vínculos entre la militancia en el movimiento de derechos humanos y en el Partido Comunista no estuvieron exentos de contradicciones. No obstante, el caso Israel pone de relieve de manera dramática los límites de una política partidaria que a todas luces iba, en primer lugar, contra su propia militancia. Pero, si la clandestinidad que imponía la dictadura obturó el debate democrático al interior del partido, con el retorno de la democracia esas diferencias irrumpirán con fuerza y el PCA entraría en crisis.

\section{Reflexiones finales}

El presente trabajo, lejos de agotar el análisis sobre el papel del comunismo en el movimiento de derechos humanos, pretende constituirse en un disparador para futuras indagaciones.

En términos generales, puso de relieve la importancia que la experiencia acumulada por los militantes políticos tuvo en la organización inicial del movimiento de derechos humanos.

De manera más específica, se destacó el rol de LADH en la coordinación y centralización de las primeras acciones colectivas de los familiares, en un contexto marcado por el desconocimiento sobre el alcance del andamiaje represivo. También, se remarcó la relación entre esas primeras medidas organizativas y el surgimiento de la Comisión de Familiares, que a la postre se autonomizará como organismo de derechos humanos. La Comisión, al igual que la $\mathrm{LADH}$, incorporó a varios familiares de reconocida militancia. 
Con el tiempo, fue adquiriendo un perfil de mayor confrontación que el de la LADH.

En relación a La LADH, se fundamentó que estaba fuertemente influida por las posiciones políticas del PCA que, por entonces, consideraba que el Gral. J. R. Videla representaba un sector dialoguista dentro de las Fuerzas Armadas. El conservadurismo de estas posiciones habría operado como un factor de retraso en la circulación del conocimiento sobre el sistema de terror estatal entre los familiares. Sin embargo, la sola presencia de militantes del PCA fue un factor que justificó el alejamiento de algunas madres ante el temor a ser tildadas de comunistas.

Como puede verse, el proceso de conformación de un campo de alianzas opositor liderado por el movimiento de derechos humanos debe analizarse en su complejidad e incluso en sus tensiones. De los elementos presentados en esta ponencia, pueden inferirse algunas contradicciones sobre las que podría profundizarse. Por ejemplo, si en los primeros años la experiencia política y abogadil de la LADH dinamizó la organización de los familiares, con el tiempo, fue quedando obsoleta frente a una dictadura de características inéditas. La renuencia a participar de las rondas de los jueves en la Plaza de Mayo o de las actividades de boicot al mundial expresaba mucho más que la necesidad de velar por la seguridad de todos. Era la consecuencia de una evaluación y una estrategia política. Luchar por los presos y los desaparecidos sin luchar contra el régimen militar. Al contrario, la renuencia inicial mostrada por las Madres de Plaza de Mayo a involucrarse en reuniones que pudieran vincularlas con la subversión fue con el tiempo superada ante la frustración frente a cada pedido realizado al gobierno sobre el paradero de sus hijos. En ese proceso, las Madres terminarán construyendo estrategias más efectivas que, teniendo como centro la acción directa mediante la ocupación de la Plaza de Mayo frente a la Casa Rosada, cuestionaban la disciplina que la dictadura exigía, conmoviendo las raíces de la obediencia.

En consecuencia, atender a las mutuas implicaciones que existieron entre los partidos políticos y los organismos permitirá avanzar en un análisis más complejo acerca de las estrategias políticas puestas en juego y sus consecuencias. Permitirá superar la fragmentación temporal y temática del campo de la historia reciente y evaluar con nuevas preocupaciones la experiencia de un movimiento que, a todas luces, fue fundante de los relatos sobre la resistencia a la dictadura. 


\section{Referencias}

CASOLA, N.; MARTUCCIO, G. El Movimiento por los Derechos Humanos en la última dictadura: ¿Nuevas formas de organización? La Historia de Familiares de Desaparecidos y Detenidos por Razones Políticas. Ponencia presentada en las XI Jornadas Interescuelas de los departamentos de Historia, Universidad de Tucumán, Facultad de Humanidades, 2007.

FUNDAMENTOS. Año 1, ago. 1976.

GORINI, U. La rebelión de las Madres. Buenos Aires: Norma, 2006.

GILLESPIE, R. Soldados de Perón: los montoneros. Buenos Aires: Grijalbo, 1987.

JELIN, E. Los nuevos movimientos sociales. Buenos Aires: CEAL, 1985. 2 v.

.Los derechos humanos entre el Estado y la sociedad. In: SURIANO, J.(Dir.). Nueva

historia argentina: dictadura y democracia (1976-1983). Buenos Aires: Sudamericana, 2005.

MEMORIA ABIERTA. Testimonio de Enrique Israel. Buenos Aires, 2001 a.

. Testimonio de Mauricio Eisenschlas. Buenos Aires, 2001b.

. Testimonio de Alberto Pedroncini, Buenos Aires, 2003a.

. Testimonio de Lita Boitano. Buenos Aires, 2003b.

POZZI, P. Por las sendas argentinas, el PRT-ERP: la guerrilla marxista. Buenos Aires: Eudeba, 2001.

VEIGA, R. Las organizaciones de derechos humanos. Buenos Aires: CEAL, 1985.

Resumen: El presente artículo pretende aportar a la construcción de una agenda de investigación sobre nuestro pasado reciente que incorpore temas que hasta el momento no fueron atendidos suficientemente. El papel de los partidos políticos, especialmente de izquierda, durante la dictadura y su vinculación con el movimiento de derechos humanos es, sin lugar a dudas, uno de ellos. Un objetivo importante de este trabajo es destacar el papel de la militancia política al interior de los organismos de derechos humanos y, más específicamente, el trabajo de los comunistas en la Liga Argentina por los Derechos del Hombre (LADH). El Partido Comunista (PCA), por entonces, sostenía que existía una puja al interior del gobierno militar entre un ala moderada, representada por Videla y Viola, y un ala derechista o "pinochetista". Frente al riesgo de imposición de los últimos, los comunistas consideraban que la defensa crítica del sector encabezado por Videla constituía el "mal menor". Explorar la traducción práctica de esta caracterización política en el plano de la militancia en la LADH es, también, propósito de este trabajo.

Palabras-clave: derechos humanos, militantes, Partido Comunista. 
Quando o "novo" é tão "velho" como o "novo" é "velho". O movimento de direitos humanos durante a última ditadura militar na Argentina. O papel do Partido Comunista e a Liga Argentina pelos Direitos do Homem (1976-1983)

Resumo: $\mathrm{O}$ artigo procura contribuir com a construção de um programa de pesquisa que incorpore questões do passado recente que até agora não foram abordadas suficientemente. O papel dos partidos políticos, especialmente de esquerda, durante a ditadura e sua relação com o movimento de direitos humanos é, sem dúvida, um deles. Um objetivo importante deste trabalho é destacar o papel do ativismo político no seio das organizações de direitos humanos e, mais especificamente, o trabalho dos comunistas na Liga Argentina por los Derechos del Hombre (LADH). O Partido Comunista (PCA), então, argumentou que havia uma briga dentro do governo militar entre uma ala moderada, representada por Videla e Viola, e uma ala de direita ou "pinochetista". Dado o risco de imposição dos últimos, os comunistas consideraram que a defesa conduzida por Videla era o “mal menor". Explorar a tradução prática desta caracterização política no plano da militância na LADH é também objetivo do presente trabalho.

Palavras-chave: direitos humanos, ativistas, Partido Comunista.

When the "new" thing is so "old" as the "new" is "old." The Human Rights Movement during the last military dictatorship in Argentina. The role of the Communist Party and the Argentine League for Human Rights (1976-1983)

Abstract: This article aims at contributing to the building of a research agenda that incorporates argentine recent past issues that, so far, have not been sufficiently addressed. The role of political parties, especially the left, during the dictatorship and its relationship with the Human Rights Movement is, undoubtedly, one of them. An important objective of this paper is to highlight the role of political activism within the human rights organizations and, more specifically, the work of the communists in the Argentine League for Human Rights (LADH). The Communist Party, then, argued that there was a bid within the military government between a moderate wing represented by Videla and Viola, and a right wing or "Pinochetist". Given the risk of imposition of the latter, the communists considered that Videla-leaded sector's critical defense was the "lesser evil". Another important purpose of this paper is to explore the practical translation of this characterization in terms of political activism in LADH.

Keywords: Human Rights, activists, Communist Party.

Recebido em 08/10/2011

Aprovado em 24/10/2011 